\title{
Is England's public health nutrition system in crisis? A qualitative analysis of the capacity to feed all in need during the COVID-19 pandemic
}

Sharon Noonan-Gunning, PhD, RD, University of Westminster; University of Chester; City University of London s.noonangunning@westminster.ac.uk

Kate Lewis, RD, Independent Public Health Nutrition Researcher

Lynne Kennedy, PhD, RNut, HonMFPH, Professor Public Health and Nutrition, University of Zayed, UAE; University of Chester, UK Lynne.Kennedy@zu.ac.ae

Jessica Swann, RD, Senior Lecturer, University of Westminster. Primary Care Dietitian, Guy's \& St Thomas's NHS Trust

Gursimran Kaur Arora, Public Health Nutritionist, University of Westminster alumni

Regina Keith, RGN, RM, RPN, MSc, SfHEA, PhD Senior lecturer, University of Westminster. Executive committee, World Public Health Nutrition Association

\section{Conflicting Interests:}

Dr Sharon Noonan-Gunning \& Kate Lewis were recipients of funding for their posts from the British Dietetic Association's General \& Education Trust. The views expressed in this article are those of the authors only: they do not necessarily represent the views of the British Dietetic Association.

\section{No Conflicting Interests:}

- $\quad$ Prof Lynne Kennedy

- $\quad$ Dr Regina Keith

- Jessica Swann

- Gursimran Kaur Arora 


\section{Abstract}

Background: This research was conducted to explore the impact of the COVID-19 pandemic on the capacity of public health nutrition services, in England, to support food insecure individuals and families, to access adequate nutritious food. Prior to the pandemic, the previous decade of government-led austerity policies had resulted in significant reductions in social sector expenditure, reducing local-level essential social services. Community groups, often labelled as the third sector, have expanded to help support local level needs for food provision, but the coverage is often reliant on lay volunteers, without adequate resources, to cope with the rising numbers of food insecure people living in England. In 2018 there were 2.2 million in Britain who were severely food insecure, by May 2020, this number increased to over 5 million. This increase was largely due to job losses and the economic impact of COVID in the UK. As the country plans its post-pandemic recovery, the lack of adequate investment in public health nutrition (PHN) services and the impact of the growing dependency on non-formal services are concerning. The present research has been conducted by a group of nutrition practitioners and academics, collectively working under the Future of Public Health Nutrition collaboration. This is exploratory research to inform future research priorities for this group and to use lessons learned to feed into future policy and practice in England.

Methodology: An exploratory methodology was adopted to examine experiences relating to capability and capacity among formal and informal helpers within the PHN domain. An online survey, mainly open-ended questions, was used to capture experiences over the period 2010 - 2020. A mixed sampling strategy, including snowball and convenience sampling, via social media and social network contact-sharing approaches, was adopted. Data was analysed using an inductive thematic approach.

Results: A total of 89 participants representing the PHN system in England were recruited over two months. Three main themes and eight sub-themes were identified. The first reflected unequivocal accounts of the impact of austerity and the inability of PHN services to meet demand for food security. The second articulated capacity and capability issues within the system, with geographical variations in service delivery, and a lack of connectivity between central, local government, and third sector providers. These were attributed to widening nutrition and health inequalities. Participants felt that the government needed to invest more technical and financial resources to support public health nutrition. They also felt that schools could play a larger role at local level, but there was a need for a clear national recovery plan, setting out a comprehensive and fully supported national strategy to eradicate food insecurity in England

Conclusions: Further in-depth research is needed to continue to track the impact of recovery strategies on food insecure people and the capacity of the PHN system. Urgent investment in the capacity and coordination of PHN services is needed to support food insecure people in England. The UK could include the ratification of the right to food in national laws, in line with global commitments already agreed to by the UK State Party.

Key Words: Public Health Nutrition, COVID-19, Service Capacity, Austerity, Third Sector, Nutrition, Community Food Services 


\section{Introduction}

Geyser (2021) presented a clear outline of the impact of COVID-19 on the inability of a growing proportion of households in England to secure sufficient nutritious food to meet basic needs. Questions are raised by Geyser (2021) and others such as the Food Foundation (2021) regarding the state of the UK's public health nutrition (PHN) system, and its capacity to promote health, through nutrition. Nutritious food can support enhanced health outcomes and prevent nutrition-related illness, such as diabetes (Nutrition Society 2021). Historically, the UK had a well-established PHN system that was underpinned by its welfare state, with social protection measures such as health services free at the point of access, free school meals and financial support for those living in extreme poverty.

Public Health Nutrition services include professionals (formal such as nutritionists) and lay personnel (informal, such as those working in community food banks) helping across a range of state and non-state agencies (known as the third sector) and civil society to protect and promote health through dietary means. Since 2012, responsibility for public health governance has been shifted away from central government to local authority control.

In the UK, PHN plays a critical role in social nutrition as part of a community-level infrastructure that brings people together, reducing isolation and maintaining mental as well as physical health across the life course. PHN prioritises all in need, those who are food insecure, suffering malnutrition or in need of nutrition for other reasons. In recent decades, community engagement was fundamental, with lay food and health workers key to the PHN strategy. Pre-pandemic, PHN had undergone dramatic changes driven by austerity policies and increases in food insecurity (Middleton, 2017; Alston, 2019) and research at local government level raises concerns around a range of governance issues (Keith et al., 2019). At the start of the pandemic, the UK Government lacked a food resilience strategy (Lang et al., 2021). Arguably, a decade of austerity policies had already undermined the capability of the system. In April 2020, The London Resilience Strategy stated 'There is not enough free food or volunteer capacity to feed all economically vulnerable people through local authority and charitable means' (Dalmeny and Pritchard, 2020). Despite the rapid response by local government public health $(\mathrm{PH})$ teams, who in partnership with third sector organisations (TSOs) set up locality food hubs, TSOs voiced concern that they did not have the resources to feed all in need from the outset. (TSOs are neither public nor private, sometimes referred to as 'not for profits'.) The inability of government to secure access to food for the population to prevent hunger and malnutrition during the pandemic has highlighted the true impact and extent of prolonged austerity-linked disinvestment in PHN, illuminating stark resource and capacity issues within the system. As Middleton (2017) articulated, a much broader crisis exists: 'The public health system in England is in its greatest period of upheaval, loss of workforce and financial resources, and loss of morale in a long time'. The impact of this pandemic on household income and the inability of many people to afford and gain access to sufficient food has exposed a weakened PHN system.

The nature and scale of the problem affecting PHN, including the potential impact on population health and services within the system, have yet to be examined. Insights on these will inform guidelines on a more resilient and prepared PHN system, which could ensure that policy makers better address the need for food security. A Future of Public Health Nutrition research collaboration was established to examine these concerns. This article reports on the first study carried out by this collaboration during the early months of the pandemic. In the context of the UK's devolved nations, it is limited to England. 


\section{Background}

\section{Right to food}

Despite the UK State Party ratifying a number of international agreements such as the OHCHR (1966) International Covenant on Economic, Social and Cultural Rights that support the right to food (which the UK State Party ratified in 1976), this has yet to be enshrined in UK law. After years of campaigning by non-government organisations (NGOs), it remains an obligation that lacks enforcement (Sustain, 2019). The legal right would entail responsibility for ensuring physical and economic 'access' to food. As set out by Marmot et al (2008) the social determinants of health such as addressing employment, nutrition and poverty need to be prioritised when seeking to improve health outcomes, especially for the most vulnerable. The UK's welfare state provided an effective range of social protection measures such as access to free education, and health services free at the point of access as well as support for social housing and income support. These measures protected the most vulnerable leading to enhanced health outcomes post 1948, however, as the investment in these measures has been reduced, the gap in inequality has widened and the needs of the most vulnerable are not being met by present government measures. Eligibility to food insecurity services and support is not universal and is mostly means-tested. There is a strong civil society and NGO presence within this domain with many lobbying for parliamentary changes to end food insecurity. A recent success (End Hunger UK, 2019) was the Department for Work and Pensions (DWP) confirming that it was planning to include household food insecurity measurement questions in its annual Food and Resources Survey. Stuckler et al. (2017) note that food insecurity has increased markedly as a direct impact of austerity measures.

\section{Austerity: the impact on public health nutrition services}

In the 1980s in the UK, there was a clear ideological shift away from collective, welfarist and social protection policies towards fundamentalist, free-market, individualist policies of privatisation and de-regulation, resulting in the gradual dismantling of the welfare state. As part of this shift, austerity measures--introduced after the financial crisis of 2008 (Stuckler et al., 2017) as budget cuts (as opposed to tax increases) as a means to reduce national deficits-further catalysed this shift away from the welfare state, further reducing central government funding for key social care services. The impact of austerity on PHN was deep, with cuts to nutrition-related services broadly felt--since nutritional health is cross-departmental involving education, community engagement, adult, children and young people's services, incorporating a broad range of professions.

Austerity measures delivered a cut of 38\% to local government budgets between 2009 and 2018 (Thomas, 2019) and PHN provision was reduced to all but essential services. In the UK historically, a range of services had been provided to ensure vulnerable people have received support and services with respect to food security. But Age UK (2015) reported that funding for 'Meals on Wheels' (food delivery services for older vulnerable adults) was cut by $47 \%$ in just three years; and Breslin (2019) noted 1000 children's centres, which provided a range of family support services including food security and nutrition, had been closed. While national school food standards exist in the UK, these are not mandatory and broad variations exist (Murphy et al., 2020). In the past, the state provided free school meals to all children, but this was restricted over time to the most vulnerable groups. Furthermore, free school meals and replacement food parcels available during the pandemic have been shown to have nutritional inadequacies (Keith, 2020; Food Foundation, 2021). 
In his report on poverty in the UK, the UN Special Rapporteur on Extreme Poverty and Human Rights (Alston, 2019) identified the socio-political context as the primary factor contributing to growing numbers unable to access sufficient supplies of food, resulting in hunger and food insecurity. He further argued that poverty is the result of political decisions, ideology and notably, austerity policies. 'For almost one in every two children to be poor in twenty-first century Britain is not just a disgrace, but a social calamity and an economic disaster, all rolled into one'. Across Europe, austerity's impact was less severe in countries with stronger social protection systems, and in this area the UK fared badly (Stuckler et al., 2017).

\section{Food insecurity: pre and during the pandemic}

Over the last four decades the definition of food security has changed from a focus on the availability of food to a more complex understanding of the factors affecting food and nutrition security. In 2002, the FAO updated the definition of food security to: 'Food security...exists when all people, at all times, have physical, social and economic access to sufficient, safe and nutritious food that meets their dietary needs and food preferences for an active and healthy life' (FAO, 2002). The impact of the COVID-19 pandemic on household income and the inability of many people to afford and gain access to sufficient food exposes shortcoming in England's PHN system. Since the first national lockdown in March 2020, the number of households unable to afford adequate food to meet basic requirements increased considerably with 'complex and severe' impacts, demonstrated by Connors et al. (2020). In 2014-15, the Trussell Trust (the UK's largest foodbank network) provided three-day emergency food supplies to 1 million people, but by 2018, still well before the pandemic, 2.2 million in Britain were severely food insecure - the highest reported level in Europe (FAO et al., 2018), indicating that tackling food insecurity was neither a political nor an ideological priority for the government.

In May 2020, the Food Foundation ${ }^{\mathrm{a}}$ (2020) estimated that nearly 5 million were affected by food insecurity. As not all those in need use food banks, the true extent is likely to be higher. Power et al. (2020) argue that this increased dependency on foodbanks is partly attributable to the $£ 30$ billion shortfall in adult social security funding, as a consequence of welfare reform. Whilst the precise nature of a relationship between COVID and poverty is unclear, the evidence of the economic impact of COVID on employment status, and thus household income and food and nutrition security, is unequivocal (Geyser, 2021). The situation was also exacerbated by food supply issues, compounded by continued and unresolved trade negotiations due to Brexit; episodic 'panic buying' and stockpiling; school closures with no access to free school meals; and reduced or decommissioned public services and funded voluntary services. As stated in The Measuring Up Report (UKSSD, 2018) 'these challenges [of ending food insecurity and achieving zero hunger] are underpinned by a food system which is struggling to provide healthy, sustainable, diverse diets for everyone in the UK.'

\section{PHN - a multidisciplinary domain}

Little or no research has examined the impact of austerity on the PHN system's service capacities or workforce. The responsibility for food security is multi-professional and cuts across many disciplines involved in social and community nutrition. For PH nutritionists, the recognition of food insecurity is a key professional competency requirement. The system relies on the skills and services of sectors outside health, including civil society and TSOs, as well as communities themselves, with an element of self-care as part of its basic structure (Kennedy et al., 2008). The relative contribution of each sector and the boundaries between 
these have changed over time, according to wider social, cultural and economic factors. While little research has examined this area, anecdotally, PHN staff, including dietitians and nutritionists, have experienced downgrading and de-professionalisation. In tandem, we have witnessed a large growth in a 'food voluntariat' of volunteer workers such as the 28,000 working at Trussell Trust foodbanks alone (Trussell Trust, 2021). Post austerity changes are undocumented and the groundswell response to the emergency food crisis in the pandemic suggests further changes in the PHN domain, as thousands of informal helpers became involved in feeding those in need.

A key question now is who occupies the PHN domain and are they adequately resourced? Throughout history, civil societies, informal helpers and self-care have supported professional or formal health systems in containing costs and meeting demand for support. Recently the addition of cadres of lay or informal helping in the form of health trainers, lay food and health workers, community link workers, community connectors and ambassadors, taking roles previously undertaken by professionals, has been seen (Kennedy et al., 2008; Kennedy, 2010). Similarly, within PHN in the UK, there was an expansion of community nutrition and dietetics during the 1980s and 1990s into community development, marking a shift for nutrition professionals in helping to address complex social issues such as food poverty previously occupied by civil society. Simultaneously, a new informal helping emerged with peer, or lay, health workers supplementing and replacing professional or formal helping (Kennedy et al., 2008; Kennedy, 2010). Despite misgivings about their effectiveness and cost efficiency, the lay helping model has, to a limited extent, survived amid changing socioeconomic and political climates. The growth in food insecurity and the civil society response, while underfunded, offers opportunities to examine the interface between formal and informal ways of maintaining the nutritional health of the population. The struggle for autonomy and control of PHN, or in the case of food insecurity, the relinquishing of state responsibility, results in challenges for public health nutrition. With these challenges in the background, we are encouraged to re-evaluate the state of the PHN system and the interdependence between professionals and lay community experts.

In summary, the overall aim of this Future of Public Health Nutrition collaborative study was to explore the capacity of PHN services since austerity, based on the experiences of the PHN workforce, and develop guidance going forward. The scope was confined to England.

\section{Methods}

A formative analysis using an integrated quantitative and qualitative survey explored perceived capacity issues among those currently working in the PHN system. This was underpinned by a realist perspective. A temporal approach was adopted to consider participants' experiences from prior to austerity and going into the pandemic.

\section{Participants}

A non-probability sample of 100 participants was established. This included those working in the public health nutrition system in a formal or informal helping role, before or at the time of the pandemic.

\section{Sampling and recruitment}

Given the multidisciplinary and multi-agency nature of the PHN system, the population is extensive but lacks a central register. Attempts were made by the team to optimise the 
opportunity for anyone working in PHN to participate, and non-randomised sampling involving purposive, convenience and snowballing techniques was used. A systematic approach to the recruitment strategy was taken. Key informants were contacted by email-both individuals and gatekeeper organisations (such as national NGOs) --with relevant membership databases to reach registered (formal) and practising (informal) representatives of the PHN workforce. Informants were encouraged to share the survey link with colleagues and peers in PHN. A Twitter account was set up with a target of engaging 200 followers within an eight-week period. Several key influential Twitter accounts were identified and included in hashtags to their followers. The account posted multiple tweets and re-tweets daily (commenting on relevant news headlines and trending topics) and engaged by direct message with accounts that commented or re-tweeted. Followers were encouraged to engage with and share the survey. This is consistent with O'Connor et al. (2014), who describe this as a variation on snowball sampling.

\section{Data collection and analysis}

An online survey was used as the primary method for data collection, combining quantitative and qualitative open-ended questions. This was hosted on JISC (a general data protection regulation-compliant higher education digital resource platform) through the University of Westminster. A semi-structured survey was used, consisting of 6 closed and 9 open-ended questions without word limit to elicit participants' views and 7 demographic and quantitative questions. The survey was designed to achieve the research aims and objectives, encouraging participants to express views on current capacity and factors perceived to influence this. Questions explored the strategic and operational solutions designed to address food security locally, including the availability of services, facilities, and resources to support this. Questionnaire design was led by SNG and KL with input from the wider project team. The final survey was piloted and refined, based on feedback regarding comprehension, relevance and face validity.

Data were exported from JISC using Excel to manage the data. Quantitative responses were pre-coded and analysed (by GA) using SPSS. Open text responses were analysed thematically and independently by the two researchers (SNG and KL), drawing on the approach of Saldaña (2016). This involved familiarisation through multiple readings of the data, analytical memos and initial coding. A process of constant comparison and member checking strengthened the trustworthiness and rigour of the analysis process. Codes, subthemes and themes were discussed for interpretation, sense check, discordance and concordance. Code lists were used to create a thematic framework and discussed with the wider team. Data were examined for patterns and connections between emerging themes, including outliers. The analysis was discussed at wider research meetings for rigour, consistency and relevance of interpretation. This process served to facilitate open discussion and acknowledgement of differing professional experiences and theoretical and ideological world views of the team and the possible impact on interpretation. The Critical Appraisal Skills Programme (2018) qualitative checklist was used to improve data quality.

\section{Ethical Approval}

Ethical approval was obtained from the University of Westminster Ethical Review Committee (Ref: ETH1920-1758) and ethical standards were adhered to throughout. 


\section{Results}

After a two-month data collection period, 105 responses were received; 16 were removed due to being pilots or incomplete, resulting in a sample of 89 participants. All 9 regions of England were represented, with the plurality (38\%) based in London, almost a fifth $(22 \%)$ in the North, and 16\% and 20\% respectively from the Midlands and East of England, and the South. For demographic characteristics, see Table 1.

Table 1. Participant roles and experience

\begin{tabular}{|l|r|l|r|}
\hline $\begin{array}{l}\text { Role or position: (more than one could be } \\
\text { selected) }\end{array}$ & & Sector: & \\
\hline Public health dietitian/nutritionist & 31 & Public sector & 39 \\
\hline Food aid worker - unpaid/intern/volunteer & 21 & Third sector & 20 \\
\hline Academic/researcher & 18 & Private sector - organisation & 9 \\
\hline Food aid worker - paid & 11 & Private practice - individual & 5 \\
\hline Health professional & 11 & Public sector \& third sector & 1 \\
\hline Education professional & 6 & Public sector \& private sector & 1 \\
\hline Public health nutrition officer & 5 & Prefer not to say & 3 \\
\hline Student & 5 & Others, not specified & 11 \\
\hline Service manager & 4 & & \\
\hline Public health professional & 2 & & \\
\hline Environmental health officer & 2 & & \\
\hline Specialist clinician & 2 & & \\
\hline Others & 8 & & \\
\hline Years of experience: & & & \\
\hline 21 or above & 26 & & \\
\hline $11-15$ & 19 & & \\
\hline $6-10$ & 12 & & \\
\hline $2-5$ & 18 & & \\
\hline $0-1$ & 11 & & \\
\hline Did not specify & 3 & & \\
\hline
\end{tabular}

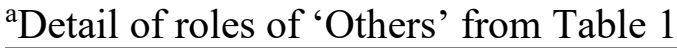

\begin{tabular}{|l|l|}
\hline Registered nutritionist & 1 \\
\hline Community centre manager & 1 \\
\hline Food producer & 1 \\
\hline Local authority officer & 1 \\
\hline Food service consultant & 1 \\
\hline Care sector & 1 \\
\hline Charity manager & 1 \\
\hline National coordinator \& campaign activist & 1 \\
\hline Total & $\mathbf{8}$ \\
\hline
\end{tabular}

Extensive qualitative data were generated by the survey, yielding $n=23,672$ words. Based on our analysis, 12 sub-themes were initially generated and refined into the framework in Figure 1. The temporal dimension of these responses was reflected in terms of 1 . Capacity of the PHN system as the pandemic arrived; 2 . The impact the pandemic had on the system; and 3. Strategic solutions proposed by participants. 
Figure 1. Themes and sub-themes

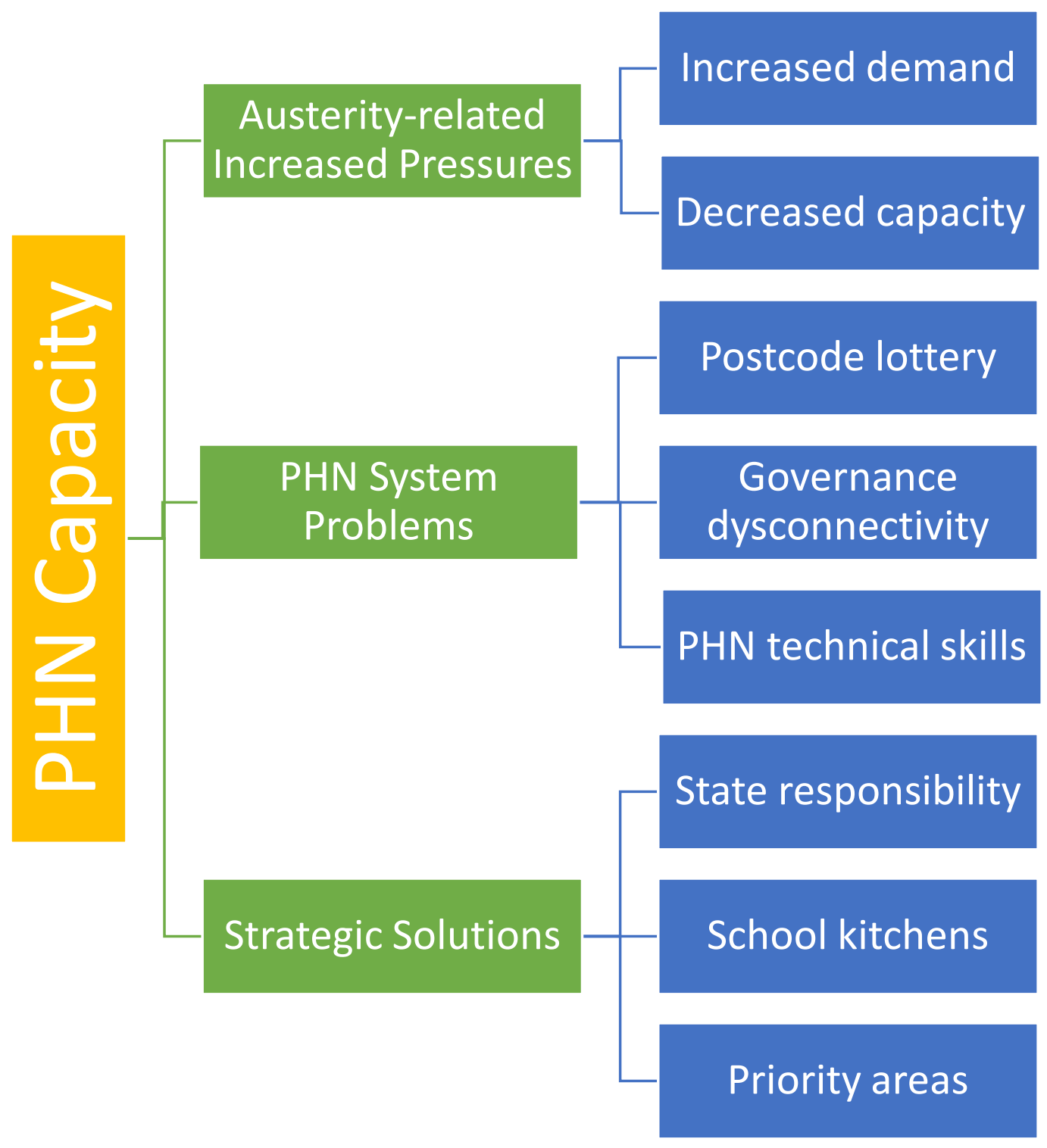

\section{Austerity-related pressures on PHN services}

It was clear that respondents considered that the PHN system was 'in crisis', as evidenced by the strain on capacity within the PHN system and the disappearance or loss of services responsible for helping address food insecurity. The strain on PHN services was, arguably, attributed to austerity policies apparent before the crisis, but exacerbated by COVID. The compound effect of the increased demand on, and the decreased capacity of, the PHN system was also evident.

\section{Increased demand}

Many detailed how socioeconomic factors and government policies drove food insecurity:

'... huge cuts to funding in public health services from sure start, child healthy eating services, and funding for adult services; all gone in our area! Also, drastic cuts to the welfare state leave people with no money for food, and no access to cooking facilities, 
gas or electric. Cuts to mental health services also affect people's nutrition' (UI-73450, Community food worker, Yorkshire)

\section{Decreased capacity}

The data suggest that capacity of the PHN system was significantly affected by budget cuts, which resulted in the restructuring of services, including the decommissioning of $\mathrm{PHN} /$ dietetic teams; loss of technical skills and expertise; cutbacks to community food provision; and the shift to short-term, short-funded projects and TSO involvement.

'Huge cuts in public health budgets. Vast reduction in funding to set up, run, organise projects. Lack of longevity in projects' (UI-724-74, Public health (PH) officer, London)

I work in a public health team in local authority. As a result of the cuts to the Public Health budget, we had to decommission several public health nutrition services ... and consequently design a new service for weight management on a significantly reduced budget ... Furthermore, there has just generally been less opportunistic funding for other food related projects such as food partnerships in line with the sustainable food places agenda' (UI-447-77, PH dietitian, Southern England)

'PHN expertise has been stripped from the LAs [local authorities] and the responsibility shifted to charities and foodbanks' (UI-592-83, PH dietitian, East Midlands)

Restructuring affected the roles of $39 \%$ of participants across all regions and sectors (most frequently by participants with the most experience in their sector $(43 \%$ of those affected had 21 or more years' experience).

'Service redesign got rid of the majority of the nutrition service ... team of 10 ...reduced to 2 ... service redesign where healthy eating team was restructured removing nutritionist ...no role ... for any leadership on nutrition. The team of healthy eating advisors...job roles changed ...to cover infant feeding, in-depth support ... despite fewer staff. Over 12 years' experience in community nutrition seems a waste to now be doing a non-nutrition related job ... simply aren't community nutrition jobs advertised. Job roles seen are often lower paid, part time or short fixed term contract' (UI-050-82, Project officer in the Northwest)

Many participants identified serious and systemic problems, including the absence of a PHN strategy; widespread and serious infrastructure issues; food supply restrictions; underfunding; limitations on access and governance failures.

'Government response was a disaster ... The school voucher scheme was a disaster ... There are severe gaps in feeding people' (UI-885-31, Academic/researcher, London).

'Very locally dependent no lead body in each area to take responsibility or lead each areas support means there will be inconsistencies across the UK' (UI-366-96, PH professional, Southwest) 


\section{PHN Systems}

\section{It's a Postcode lottery!}

A lack of coherent strategy was viewed as creating a 'postcode lottery' (a local or regional variation due to funding allocation) and was expressed by many participants as a consequence of diminished resources, overdependence on TSOs and local food networks, inconsistent and uneven distribution of supplies to foodbanks and community hubs.

'Processes being different in different boroughs, different provisions available' (UI799-16, PH dietitian, London)

Food provided was frequently culturally- or age-inappropriate and of poor nutritional quality, often with no choices or hot meal provision:

'We welcomed the government parcels but they were nutritionally inadequate' (UI734-50, Community food worker, Yorkshire)

'The food parcels provided did not meet cultural dietary needs, personal preferences. We do not know if people used the ingredients/food provided. In some cases, people might not even have access to a kitchen' (UI-844-68, Public health nutrition (PHN) officer, London)

'... councils in the areas that I'm aware of were able to start providing food provision this was often not particularly nutritious food and it wasn't of the highest quality it was often long-life food that didn't reach the nutrition needs' (UI-000-106, National charity co-ordinator)

The random nature of the food distributed made it difficult for users to cook, amplified by this participant:

'Some weeks we had bread mountains from donations. Supplies by the council were sometimes very poor and we know that it has been a struggle to provide culturally sensitive food. Sadly, some of the fresh fruit and vegetables were rotten even before we received them for distribution... we distribute to over 120 households' (UI-848-72, Community Centre Manager, London)

It was noted that there was a difference in the level of access to effective PHN services often due to geographic determinants, often referred to as a 'postcode lottery' in the UK, and that political priorities of local government influenced this support

'It wholly depends upon the political influence in each LA. In my borough there has been no cuts to public health nutrition and in fact it has been strengthened' (UI-88915, PH nutritionist, London)

'Some local authorities approached the issue with vigour whereas others as more of an obligation and seen as a 'success' that 3rd sector food banks fed so many people!' (UI-59138, PH nutritionist, London) 


\section{Governance dysconnectivity}

Many identified governance issues, including disconnected relationships within partnerships, in particular at the level of engagement with the community:

'Conflicts/tensions have occurred between local authorities 'new' to providing food assistance and third sector, 'used' to this, data not always shared, cooperation becomes strained, perception of 'need' being met different[ly]' (UI-383-14, Researcher and PH dietitian, East of England)

'Our county is large and I have a realised we have a distinct lack of communication from a local district level, up to the county level around food insecurity' (UI-447-77, PH dietitian/nutritionist, South of England)

'The joint working helped but there was a lack of information who was doing what that made our local response more difficult' (UI-271-84, PH dietitian, Yorkshire)

Several participants stated that community involvement had been overlooked, with many citing a lack of 'engagement' as critical to the crisis in the PHN system's ability to meet community's nutritional needs:

'Ensuring that all groups within a community are given the opportunity to be involved...smaller groups often get left out' (UI-604-53, Service manager in community food, West Midlands)

'Put food on the agenda and make it LOCAL. Charities can support the local organisations / groups deliver but they shouldn't hijack!' (UI-844-68, PH nutrition officer, London)

While many spoke of structural problems, some identified positive experiences with local solidarity and mutual caring, especially where local partnerships were able to feed large numbers of food-insecure groups and individuals.

'I'm the head of a big primary school in the South West-we had an amazing response from local partnerships' (UI-861-98, Education Professional)

A few referred to competition for finite resources between community groups and larger charities:

'We often feel that a lot of emphasis is placed on big national organisations such as

Trussell Trust' (UI-604-53, Service manager in community food, West Midlands)

\section{PHN technical skills}

A few critiqued the absence of nutrition technical skills with an apparent lack of food needsassessments:

'Any nutritional advice or support that does not assess the need of the community it provides for - does not consider budget/cultural appropriateness ... Food banks without accountability - here one day, gone the next' (UI-266-20, PH dietitian, London) 
Others cited a 'free for all' or lack of leadership or regulation as a contributing factor:

'Everyone now believes they are an expert in food poverty' (UI-889-15, PH nutritionist and service manager, London)

\section{Strategic solutions}

\section{State Responsibility}

When asked to visualise how feeding all in need might be achieved, there was a clear call for state leadership and responsibility, particularly in respect of the role for school kitchens during lockdown. As Fig 2 illustrates, the majority (94\%) agreed that the state needed to take lead responsibility.

Figure 2. Responses to 'Do you agree the right to food for ALL should be a key responsibility of the state?'

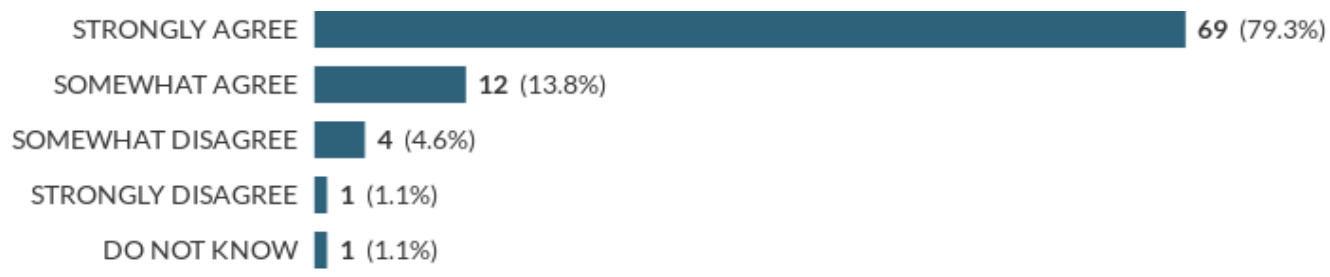

Rich data emerged around the consideration of food as a human right and the idea that keeping the general population well-nourished is in the broader interests of society:

'Not to have access to adequate food (including quantity and quality) is one of the most significant disadvantages in life. Food is a fundamental right. At the moment, food insecurity in the full sense of the term sits in the periphery of many organisations. Responsibility needs to be taken by Government' (UI-447-77, PH nutritionist, South of England)

'Absolutely, this should be true everywhere, but particularly in such a wealthy country which has the resources. It would also mean the government has to take more responsibility for food insecurity in the UK rather than outsourcing this to charity' (UI-799-16, PH dietitian and service manager, London)

\section{School kitchens}

The experience of school meals during COVID was frequently cited as a missed opportunity for feeding all in need and an example of a system in crisis through lack of government coordination and responsibility. As shown in Figure 3, a large majority (83\%) agreed that school kitchens should be used to feed people in need during the crisis as part of a national, regional and locally coordinated food strategy.

Many opinions underlying this finding supported the idea that school kitchens are ideally located in communities and well-resourced: 
'It's logical and common sense to utilise school spaces and kitchens. The school community understand the needs of their local population better and are more likely to reach those that really need help' (UI-844-68, PHN officer, London)

'It's non-sensical that school premises are not utilised properly. They are a community hub, empty for 12 weeks a year - why aren't they used efficiently? Schools standing empty during the holidays is a waste of money and resources' (UI-724-74, PHN officer, London)

Figure 3. Responses to 'Use of school kitchens as a strategy to feed all in need'

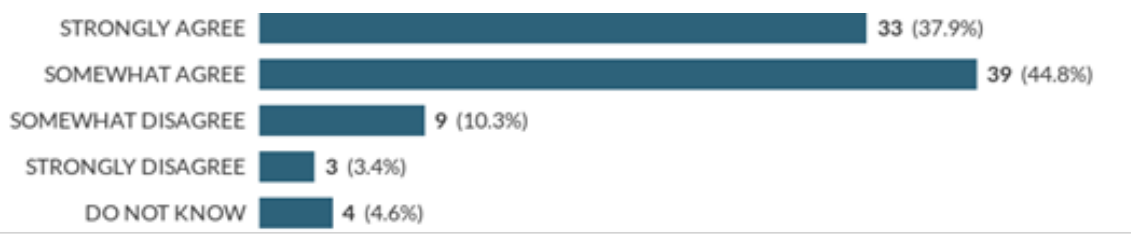

The use of local kitchens involved larger food policy issues, for many participants who suggested their use could aid sustainability and universality, facilitate a bottom-up approach to strategy, and promote commensality. However, a few held reservations or disagreed, due to safeguarding concerns (concerns about children's welfare and protection from harm), and logistical challenges.

\section{Priority areas}

Participants were asked to draw on their experience of the first lockdown to consider what had worked well, what had not worked well, and what solutions they would prioritise. Views included tackling the structural problems around living income (in terms of both wages and welfare) to enable everyone to afford to purchase food. The theme of a coordinated PHN national strategy was central. Key elements of this were increased government spending on community nutrition services across all age groups, better communication and pathways throughout the PHN system, and connecting locally-based solutions, including surplus food redistribution and local food businesses.

'Coordinated approach to have every borough providing similar services' (UI-55771, PH nutritionist, London).

'Local solutions that adapted to local needs - e.g., amending emergency food parcels to suit different dietary/nutritional needs, local groups setting up hot food delivery for sections of the community, mutual aid groups arranging shopping for isolated residents' (UI-104-63, PH specialist in the Northwest)

'Put in place well-funded, place-based programmes of work created with communities to address inequality and/or child poverty' (UI-017-28, PH Consultant, the Midlands)

"The [XX] Community Hub which was created due to the pandemic I feel should be permanent (as long as support is needed) as this is a great central hub for signposting as well as data collection for monitoring and evaluation. Having more accountable, long term food banks or food distribution sites. Always including local communities in 
decision making and advising on support needed. Free School meals to continue throughout the whole year' (UI-596-18, PHN officer and volunteer, London)

The role of inclusive PHN workforces with mixed skills was recognised. Ten participants worked as volunteers in nutritional projects and their responses show a strong understanding of the food needs of communities and strategic questions around surplus food distribution:

'Involvement of dietitians and public health nutritionists in paid rather than volunteer posts. More investment in a robust infrastructure. Right now, there is very much an 'ad hoc' approach being seen locally to the provision of food for foodbanks and it is a bit 'hand to mouth'. More information is needed on nutrition and advice for vulnerable groups and nutrition and general health training for volunteers with no background in basic nutrition and nutrition related health conditions-Diabetes, Obesity' (UI-528-57, Community food worker, Northwest England)

'Appoint a specialist in Public Health Nutrition to spearhead and prioritise the changes needed and allocate some funding for urgent national interventions' (UI043-59, Volunteer community food worker and health professional, West Midlands)

\section{Discussion}

This research offers a unique insight into the capacity of the PHN system, in England, from the view of those who are providing these PHN services, to feed all in need, during the COVID-19 pandemic. In taking a temporal view, the changes within this system, both leading up to and during COVID, and the impacts on services and communities, have been captured. Participants articulated a persistent and cumulative erosion of resources and capacity over time, which has undermined the ability to meet society's obligation to secure adequate access to food and nutrition security for all in need. This clearly contributed to growing numbers experiencing hunger, long-term implications for nutrition-related health, and widening inequalities. The impact of market-based policies in contributing to the compromised capacity of England's PHN system, and specifically its ability to protect food and nutrition security in a national emergency, is highlighted. Furthermore, inadequate financing and capacity has served to shift responsibility away from an under-resourced formal sector towards greater reliance on informal helping. This changing landscape has resulted in the institutionalisation of the voluntary and third sectors to deliver on food security objectives, without adequate funding, technical support and overall coordination and this suggests a PHN system in crisis.

There was overwhelming consensus ( $87 \%$ of respondents) that the impact of austerity-related cuts to PHN services were severe, or moderate to severe. The theme 'Increased Pressure' captures a deep unequivocal frustration with the continued erosion of the funding and resources available to support communities in need. Experienced public health nutritionists and dietitians $(\mathrm{n}=21)$ and formal helpers, with considerable experience (at least 11 years', of whom nine had 21 or more years') in the PHN domain were, not surprisingly, most vocal. They described the impact of the restructuring (underpinned by market-based policies) that undermined PHN's health prevention focus--a likely unintended consequence of policy. While this is not new to the $\mathrm{PH}$ literature, it is not widely discussed in relation to PHN. The weakening of governance infrastructures and fragmentation of service delivery was articulated in this research as a 'postcode lottery'. Graley et al. (2011) identified this in public health and public resources and Thompson et al. (2020) noted its presence in the emergency 
food aid system. Following the transfer to local government of responsibility for PH in 2013 (which dovetailed with the introduction of austerity policies in 2010), tensions in capacity were identified. Buck (2015) showed local government being unable to meet public health outcomes and Thomas (2019) observed 'it will take until approximately 2027 for public health budgets to recover from austerity and return to their 2014 levels'. This research provides insight into the austerity 'efficiency drives' led by competitive tendering and the transfer of PHN to the third sector that have advanced neither health promotion nor the workforce, instead, compromising population nutritional health and creating precarity in both food security and the working life of PHN professionals. The research also raises concerns regarding the capacity of the system to support the provision of nutritious food, which is essential for health and wellbeing. This concurs with the findings from the UKSSD (2018) research. Keith (2020) also clearly sets out the negative impact of reduced government investment in nutritious school meals resulting in long term poorer health outcomes.

As the pandemic took hold, TSOs were forced to assume responsibility for feeding vulnerable groups. Whilst a heroic achievement (the breadth of active engagement in feeding the most vulnerable was outstanding), there was deep concern around their capacity and sustainability. Although a few local authorities strengthened services and the third sector demonstrated agility at developing local solutions to feed large numbers, systemic fault lines were evident due to the deficit in capacity and the absence of a national strategy.

During the initial lockdown, a range of problems were articulated that demonstrate the systemic problems facing PHN involving governance, lack of strategy, and regional variations in access to food and service delivery. Lambie-Mumford et al. (2020) highlighted this in their evaluation of the devolved countries of the UK, noting that 'the use of funds and responses vary across local areas'. A lack of nutrition skills and dysconnectivity were observed across partnerships, particularly between larger institutions or charities and community or grassroots organisations. That some participants identified a need for recipe ideas to apply to emergency food is telling of the lack of strategic expertise around accessibility.

Also of concern was the lack of community involvement to identify needs, as voiced by several participants who reported a lack of connection between statutory and community groups, along with suggesting place-based solutions such as a community assets approach. While community engagement is a critical component in a strategy to meet a population's nutritional needs, an overarching finding of this research suggests this is inconsistent. During the 2000s, lay food and health workers, integrated into the work of community initiatives and community dietetics including Sure Start, provided key links in the system to identify community needs in concert with PHN professionals with the power and resources to support action (Kennedy et al., 2008). Now much of this has been lost due to the public sector spending cuts that have hit PHN services across all age groups.

It was interesting to note that those commenting on issues in a technical capacity were professionals. They criticised the current PHN system as a 'free for all' 'without leadership', and questioned the contribution of informal helping. For a plural system such as PHN to be effective, all sectors and actors within the system must embrace the contribution and worth of each other. Normative views of food security and the PHN domain will need to be reevaluated and the valuable contribution of informal helping both acknowledged and rewarded, without expecting they can take over tasks for which they do not have adequate training. 
Going forward, these strengths and weaknesses concur with studies revealing that the PHN system in England has structural problems in its governance that not only hinder its capacity to maintain the population's nutritional health, but, effectively, widen health inequalities. Indeed, the postcode lottery is a fault line in the PHN system, illustrated by the consensus among our respondents, that feeding all in need should be a central state responsibility, supported by state funding for sustainability. Only the state has the resources to ensure this right to food. Similarly, the consensus for the use of school kitchens as part of a national strategy illustrates support for a funded and coordinated approach to feeding all in need. Keith et al. (2019) found weaknesses in public health governance systems at the local level in relation to infant feeding. This current study--through the lens of food insecurity--raises serious concerns about the capacity of the system to provide a strategy to prevent food and nutrition insecurity--the primary function of the PHN system.

The present study also provides insight into the potential for old strategies to come together with new ones. An old approach would be the return to a strong welfare state. This was shown by support for the use of school kitchens in crisis situations (as some argued, school kitchens lie unused for much of the year) and for welfare reform sufficient to enable the population to afford to buy food. Participants also supported an increased role of the state in supporting the reduction of food insecurity and a more formalised approach to implementing global agreements ratified by the UK to protect the right to food. Schools are framed as community hubs; while there is government support for wider use of sports facilities, this is not the case for school kitchens (GOV.UK, 2020). Failure to allow access prevents the PHN system from linking with communities to tackle food insecurity. These findings are in line with research on reducing food insecurity in children over the holidays by using schools to run holiday camps providing free nutritious food (Keith and Nasser, 2018).

A new strategy should be based on connectivity to embrace the new, diverse PHN workforce, including both formal (professional) and informal (including self-care and experienced lay workers) paying attention to a bottom-up approach. Insight into the capacity of the system is provided by the experience of the unpaid PHN workforce. These unpaid roles are in contrast to the paid lay food and health workers in the 2000s where, as Kennedy et al. (2008) point out, resource constraints were driving the search for cost-effective alternatives. While not a consistent strategy regionally, this was a step forward in connecting the established nutrition system with its communities. We posit that political drivers have pushed PHN further towards a model based on cost-saving--that is a voluntary, unpaid workforce--at the expense of genuine service needs. On balance, while the PHN system has fault lines constraining its ability to tackle food insecurity, opportunities exist to redefine the PHN system in England along with the terrain of its workforce. However, the current political trajectory suggests a continued shift to the third sector with an over-reliance on the third sector and an unpaid workforce.

\section{Conclusions}

Pressures on the PHN system through food insecurity and neoliberal policies are likely to continue and deepen, owing to the economic fallout of COVID-19 and the pro-market approach of the Government's new Office for Health Promotion (Gov.UK, 2021). This does not bode well for population nutritional health. We suggest that market-based, austerity-led policies have shifted PHN away from professionalism, indeed from paid food and health work. This privatisation and charitisation process has repercussions for the wider PH system. 
The transformation of the PHN system cannot be proved in this study--limited as it is by its exploratory nature--but it does provide key insights into these processes by illuminating the frontline experience of professional and lay experts. Critically these point to a weakened, fragmented system that lacked governance and the capacity to feed all in need when the pandemic hit.

The current system is disconnected, with ad hoc services, lack of coordination or leadership, and inadequate technical and economic support. A stronger, more resilient system needs to be built, and fully funded by central government, with firm and clear guidelines for the provision of PHN, which all local authorities should follow. Currently, the trajectory for nutritional population health is concerning, given the system's weak and fractured state identified in this study. Pre-pandemic, 8 million people were living in food poverty with an additional 3 million living with malnutrition in the UK (FAO, 2016; BAPEN, 2018). Beyond our research, the pandemic has exposed the nutrition crisis facing children with the inadequate and fractured free school meal system and at least 1.7 million children exposed to food poverty during the pandemic (Food Foundation ${ }^{\mathrm{b}}$, 2020; Keith, 2020).

Future research should focus on changes in the terrain, the workforce and the disconnect with community. A reconnected system would enable local nutrition 'knowledges' that could identify and address needs.

As this research demonstrates, there is strong support for the state to take responsibility; to develop a national food strategy; and for the right to food to become enshrined in UK law. Calls for this are well-established in the UK (Sustain, 2020) and while some are calling for a Minster for Hunger (Trussell Trust, 2019), others propose that the Right to Food should be enabled by the duty of a Secretary of State (and in the devolved administrations) to ensure food security and establish an independent and fully resourced Food Standards and Security Agency (Byrne, 2021).

Despite the alarming insights provided by this novel research, it demonstrates that an expanded and diverse PHN workforce exists within myriad groups and networks, with professionals and experienced lay workers having detailed and vast understanding of the problems and solutions. Opportunities are thus opened to redefine and rebuild the PHN system. 


\section{References}

- Age UK. 2015. Older people stripped of their meals on wheels. Age UK. https://www.ageuk.org.uk/latest-news/archive/older-people-stripped-of-their-mealson-wheels/

- Alston P. 2019. UN Special Rapporteur's Report on extreme poverty and human rights. 2019. UN General Assembly, Human Rights Council. https://undocs.org/A/HRC/41/39/Add.1

- BAPEN. 2018. Introduction to malnutrition. BAPEN. https://www.bapen.org.uk/malnutrition-undernutrition/introduction-tomalnutrition?start $=4$

- Breslin D. 2019. The results of cuts and children centres closures. Action for Children. https://www.actionforchildren.org.uk/news-and-blogs/policyupdates/2019/june/the-result-of-cuts-and-children-s-centre-closures/

- Buck D. 2015. Cuts to Public Health spending: the falsest of false economies. Kings Fund. http://www.kingsfund.org.uk/blog/2015/08/cuts-public-health-spending-falsestfalse-economies

- Byrne I. 2021. Delivering a right to food for the UK. https://www.ianbyrne.org/rightto-food

- Connors C, Malan L, Canavan S, et al. 2020. The lived experience of food insecurity under Covid-19. A Bright Harbour collective report for the Food Standards Agency. https://www.food.gov.uk/sites/default/files/media/document/fsa-food-insecurity2020 -report-v5.pdf

- Critical Appraisal Skills Programme. 2018. Qualitative checklist. CASP. https://caspuk.net/casp-tools-checklists/

- Dalmeny K, Pritchard C. 2020. Food for vulnerable people in Covid-19 lockdown. Learning from Greenwich Briefing for local authorities and Local Resilience Forums working in partnership with local community and voluntary organisations. Sustain. https://www.sustainweb.org/publications/food_for_vulnerable people in_covid_lock down/

- End Hunger UK. 2019. Campaign win! UK government agrees to measure household food insecurity. https://www.endhungeruk.org/2019/02/27/campaign-win-ukgovernment-agrees-to-measure-household-food-insecurity/

- FAO.2002. The State of food insecurity in the world. Rome, FAO. http://www.fao.org/3/y7352e/y7352e00.htm

- FAO. 2016. Methods for estimating comparable rate of food insecurity experienced by adults throughout the world. FAO. http://www.fao.org/publications/card/en/c/2c22259f-ad59-4399-b740-b967744bb98d/

- FAO, IFAD, UNICEF, WFP, WHO. 2018. The State of Food Security and Nutrition in the World 2018. Building climate resilience for food security and nutrition. Rome, FAO. http://www.fao.org/3/I9553EN/i9553en.pdf

- Food Foundation ${ }^{\mathrm{a}}$. 2020. Food insecurity and debt are the new reality under lockdown. https://foodfoundation.org.uk/new-food-foundation-data-food-insecurityand-debt-are-the-new-reality-under-lockdown/

- Food Foundation ${ }^{\mathrm{b}}$. 2020. Five million people living in households with children have experienced food insecurity since lockdown started. https://foodfoundation.org.uk/new-food-foundation-survey-five-million-peopleliving-in-households-with-children-have-experienced-food-insecurity-sincelockdown-started/ 
- Food Foundation. 2021. A crisis within a crisis: The impact of covid-19 on household food security. https://foodfoundation.org.uk/wp-content/uploads/2021/03/FF_Impactof-Covid_FINAL.pdf

- Geyser L. 2021. The impact of COVID-19 on food security: A qualitative analysis of the rise in London's existing food insecurity due to the financial impact of Covid-19. World Nutrition. 12(1):40-50. https://doi.org/10.26596/wn.202112140-50

- Gov.UK. 2020. Schools encouraged to open up sports facilities all year round. Gov.UK. January 26, 2020. https://www.gov.uk/government/news/schoolsencouraged-to-open-up-sports-facilities-all-year-round

- Gov.UK. 2021. New Office for Health Promotion to drive improvement of nation's health. https://www.gov.uk/government/news/new-office-for-health-promotion-todrive-improvement-of-nations-health

- Graley C, May K, McCoy D. 2011. Postcode lotteries in public health - The NHS health checks programme in North West London. BMC Public Health. 11(1):1-8. https://doi.org/10.1186/1471-2458-11-738

- Keith R. 2020. Marcus Rashford: A brief history of free school meals in the UK. The Conversation. https://theconversation.com/marcus-rashford-a-brief-history-of-freeschool-meals-in-the-uk-140896

- Keith R, Nasser I. 2018. Assessing the impact of holiday clubs on the reduction in learning loss in the London Borough of Tower Hamlets: A Policy Brief University of Westminster London.

- Keith R, Ujah Mba E, Li X, et al. 2019. Exploring infant and young child feeding (IYCF) practices and perceptions in Tower Hamlets. World Nutrition. 10(3):26-50. https://doi.org/10.26596/wn.201910326-50

- Kennedy L. 2010. Benefits arising from lay involvement in community based public health initiatives: Experience from community nutrition. Perspectives in Public Health. 130(4):165-72.

- Kennedy L, Milton B, Bundred P. 2008. Lay food \& health worker (LFHW) involvement in community nutrition and dietetics in England: Definitions from the field. Journal of Human Nutrition and Dietetics. 21:210-224

- Lambie-Mumford H, Loopstra R, Gordon K. 2020. Food vulnerability during Covid19: Mapping responses to risk of rising food insecurity during the Covid-19 crisis across the UK. SPERI. http://speri.dept.shef.ac.uk/wp-content/uploads/2021/03/FoodVulnerability-During-the-COVID-19-Crisis-first-project-report.pdf

- Lang T, Millstone E, Marsden T. 2021. An open letter on the food emergency to the prime minister and government. https://foodresearch.org.uk/wpcontent/uploads/sites/8/2021/01/Open-Letter-on-the-food-emergency-to-the-PrimeMinister-and-Government.pdf

- Marmot N, Friel S, Bell R, et al. 2008. Closing the gap in a generation: health equity through action on the social determinants of health. The Lancet. 372(9650):16611669. https://doi.org/10.1016/S0140-6736(08)61690-6

- Middleton J. 2017. Public health in England in 2016 - the health of the public and the public health system: A review. Br Med Bull. 121(1):31-46. https://doi.org/10.1093/bmb/ldw054

- Murphy M, Pallan M, Lancashire E, et al. 2020. The Food provision, culture and environment in secondary schools (FUEL) study: protocol of a mixed methods evaluation of national School Food Standards implementation in secondary schools and their impact on pupil's dietary intake and dental health. BMJ Open. 10(10):e042931. http://dx.doi.org/10.1136/bmjopen-2020-042931 
- The Nutrition Society. 2021. Public health nutrition. https://www.nutritionsociety.org/publications/public-health-nutrition

- O'Connor A, Jackson L, Goldsmith L, et al. 2014. Can I get a retweet please? Health research recruitment and the Twittersphere. Journal of Advanced Nursing. 70(3):599609. https://doi.org/10.1111/jan.12222

- OHCHR. 1996-2021. International Covenant on Economic, Social and Cultural Rights. https://www.ohchr.org/en/professionalinterest/pages/cescr.aspx

- Power M, Doherty D, Pybus K, et al. 2020. How Covid-19 has exposed inequalities in the UK food system: The case of UK food and poverty. [version 2; peer review: 5 approved]. Emerald Open Res. 2:11. https://doi.org/10.35241/emeraldopenres.13539.2

- Saldaña J. 2016. The coding manual for qualitative researchers. $3^{\text {rd }}$ ed. Thousand Oaks, CA: Sage

- Stuckler D, Reeves A, Loopstra R, et al. 2017. Austerity and health: the impact in the UK and Europe. European Journal of Public Health. 27:4.

- Sustain. 2019. The alliance for better food and farming. The right to food. April 23, 2019. https://www.sustainweb.org/righttofood/

- Thomas C. 2019. Hitting the poorest worst? How public health cuts have been experienced in England's most deprived communities: An ounce of prevention is worth a pound of cure. IPPR. November 5, 2019. https://www.ippr.org/blog/publichealth-cuts

- Thompson E, Spoor E, Weal R. 2020. Local Lifelines: Investing in local welfare during and beyond Covid-19. The Trussell Trust. https://www.trusselltrust.org/wpcontent/uploads/sites/2/2020/10/LWAS_1020_v3.pdf

- Trussell Trust. 2016. Feeding Britain one year on: Update from the Trussell Trust. https://www.trusselltrust.org/wp-content/uploads/sites/2/2016/01/Submission-toFeeding-Britain-1-year-on-Trussell-Trust-final-1.pdf

- Trussell Trust. 2019. The Trussell Trust responds to environmental audit committee's report. January 10, 2019. https://www.trusselltrust.org/2019/01/10/trussell-trustresponds-environmental-audit-committees-report/

- Trussell Trust. 2021. The State of Hunger 2021. https://www.trusselltrust.org/wpcontent/uploads/sites/2/2021/05/State-of-Hunger-2021-Report-Final.pdf

- UKSSD. 2018. UK Stakeholders for Sustainable Development. Measuring up: how the UK is performing on the UN Sustainable Development Goals. https://www.ukssd.co.uk/measuringup 